\title{
Playing To Their Strengths: Empowering Students With Flexible Assessment
}

\author{
Ashley Edwards \\ Corresponding author: Ashley.Edwards@utas.edu.au \\ School of Biological Sciences, University of Tasmania, Hobart, Tasmania, 7000, Australia
}

Keywords: autonomy, flexible assessment, engagement, motivation, student choice

\begin{abstract}
Assessment strategies play a major role in enhancing motivation and engagement. In this study, I offered second year biology students the opportunity to take increased control over their semester-based assessment by voluntarily adjusting the weightings of individual assessment items. Students self-reported on their levels of engagement and motivation in the unit. Most respondents (96\%) agreed it was appropriate that students were able to adjust task weightings. Students reported feeling ownership and responsibility for their learning as positive factors increasing their desire to direct effort into learning opportunities and assessment tasks. Others reported that increased autonomy reduced the stress and anxiety associated with assessment. $47 \%$ of students who returned the survey elected to adjust their assessment. The rest did not want the responsibility of making the 'wrong' decision, raising the question of the timing of such initiatives: at what stage in their learning journey are students ready to take on that level of responsibility for their own learning? Self-reported reductions in levels of stress and anxiety associated with assessment by student participants suggest that flexible assessment opportunities could be valuable tools in enhancing the effectiveness of engagement strategies in tertiary learning environments, particularly as the nature of those learning environments continues to change.
\end{abstract}

\section{Introduction}

Student expectations of their higher education experiences are changing rapidly: educators must adapt to meet the varying needs of their students (Ahlfeld, Mehta \& Sellnow, 2005). Students are expected to develop and demonstrate skills, knowledge and numerous other attributes over a sustained period of time each semester, requiring that learning activities and programs are both motivating and engaging (Martin, 2009). Assessment of these skills, knowledge and attributes must be authentic (Hart, Hammer, Collins \& Chardon, 2011), constructive to learning, via appropriate and timely feedback (Gibbs \& Simpson, 2004), valid, by maintaining accountability, transparency and clarity (MacLellan, 2004) and accessible to all, including those with physical disabilities and cohorts such as international students (Irwin \& Hepplestone, 2011; Rust, 2002).

Self-determination theory (SDT) suggests that all people possess an inherent need to feel in control (Ryan \& Deci, 2000): this applies strongly to educational situations in which feelings of autonomy are central to levels of motivation (Utman, 1997). Intrinsic motivation, that is, learning aimed at gaining mastery or satisfying curiosity (Flink, Boggiano \& Barrett, 1990), demonstrably leads to superior performance and enhanced learning outcomes compared with extrinsic sources of motivation (including learning in order to achieve performance goals (Utman, 1997). In other words, the carrot is likely to yield better outcomes than the stick. Students participating in learning opportunities 
because they are actively engaged are more likely to feel competent and effective than those who are focussed primarily on passing a test (Deci, Nezlek \& Sheinman, 1981).

Assessment can dominate student attitudes towards learning (Cook, 2001; Gibbs \& Simpson, 2004) and can come to define what students perceive as important aspects of their learning (Rust, 2002; MacLellan, 2001). Assessment often causes significant stress and anxiety (Ryan \& Deci, 2000), which can have negative effects on motivation and engagement in learning activities (Gibbs, 1992). Stress, or perceived stress related to assessment tasks, can reduce motivation (Brown, Bull \& Pendlebury, 1997), impair performance (Hart, Hammer, Collins \& Chardon, 2011; Flink, Boggiano \& Barrett, 1990) and negate other engagement strategies (Gibbs \& Simpson, 2004).

Heightened motivation to learn comes from active personal commitment, and one of the key factors known to enhance motivation to learn is choice. Choice creates feelings of power and autonomy, which have a positive impact on motivation (Ryan \& Deci, 2000). The freedom to select, from a range of options, what suits an individual best, enhances student interest, active participation (Rust, 2002) and the inclination to explore, learn and express creativity (Ryan \& Deci, 2000). Choice in assessment is a valid learning and teaching tool with which to harness and amplify student motivation by encouraging students to take greater responsibility for, and control of, their learning (Cook, 2001). This increased autonomy can change a student's perception of their learning experiences (Zepke \& Leach, 2010). Many tertiary educators already offer assessment choice via internal choice in examination questions. However, the term 'flexible assessment' can also be applied when students choose: which or how many tasks to complete (Cook, 2001) how those tasks might be presented and skills demonstrated (Irwin \& Hepplestone, 2012), when to complete them, the weighting for each task (Wood \& Smith, 1999), or even when crafting their own assessment criteria (Caitlin, Lewan \& Perignon, 1999). The challenge with such student choice can be to ensure that students still have the opportunity to experience, and demonstrate appropriate mastery of all required skills, content and Intended Learning Outcomes (ILOs).

This research project explored student uptake and perceptions of flexible assessment opportunities in a second year zoology unit. Students were able to 'play to their strengths' by selecting to more heavily weight tasks at which they believed they could perform strongly, whilst still being required to complete all set assessment tasks and therefore address all unit ILOs. I evaluate, using a voluntary survey technique, the impact of choice in assessment weighting on self-reported levels of engagement and motivation in students. I offer reflections on the ways in which flexible assessment influenced student perceptions of their learning and assessment opportunities, the factors influencing student decisions about flexible assessment and possible future directions for the delivery of this flexible assessment initiative.

\section{Methods}

The concept of flexible assessment was introduced to the students in week 1 of a 13 week, Semester 2, 2014, second year Zoology unit in the School of Biological Sciences (SBS), University of Tasmania (UTAS). At the start of the first face-to-face practical session (week 1), the opportunity to adjust assessment weightings being offered and the parameters were explained. This information was repeated in an increasingly abbreviated form at the start of practical classes in weeks 2, 3, 4 and 5 of semester, with regular 
references to the relevant written information included in the unit outline. All students enrolled in the unit $(n=82)$ were offered this opportunity, regardless of whether they intended to participate in any subsequent surveys for data collection.

Students were offered the flexibility to adjust the relative contributions of two equally weighted assessment tasks towards their final result. The standard assessment pattern for the unit included two semester-based assessment tasks each worth $20 \%$ of their final grade. Students could elect to adjust the weighting of these tasks by $5 \%$ (one up and the other down, as summarised in Table 1). The two contrasting assessment tasks involved were a written research assignment and an end-of-semester practical test. These were selected because they were of equal weighting, and because they provided numerous points of contrast to aid students in making their decision, including start and due dates, duration, the nature of the task (hands-on practical activities under open-book test conditions or a research-based writing task), and the form of assessment (in-class test or a written assignment done at home). The ILOs assessed by each task were drawn from the same pool of unit ILOs and had some overlap (Table 1).

Table 1. Flexible assessment patterns available to students

\begin{tabular}{|c|c|c|c|c|c|}
\hline Task & Timing & $\begin{array}{c}\text { Option } 1 \\
\text { (standard) } \\
(\%)\end{array}$ & $\begin{array}{c}\text { Option } 2 \\
\text { (\%) }\end{array}$ & $\begin{array}{c}\text { Option } 3 \\
(\%)\end{array}$ & Unit ILOs addressed \\
\hline $\begin{array}{l}\text { Scientific } \\
\text { manuscript }\end{array}$ & $\begin{array}{l}\text { Commenced } \\
\text { week } 4 \\
\text { Submitted } 3 \\
\text { weeks later }\end{array}$ & 20 & 25 & 15 & $\begin{array}{l}\text { communicate effectively } \\
\text { using a range of formats } \\
\text { relevant to scientists } \\
\text { accurately collect } \\
\text { scientific data/evidence } \\
\text { and use it to solve } \\
\text { problems }\end{array}$ \\
\hline $\begin{array}{l}\text { Practical } \\
\text { test }\end{array}$ & $\begin{array}{l}\text { Week } 13 \\
\text { practical } \\
\text { session }\end{array}$ & 20 & 15 & 25 & $\begin{array}{l}\text { communicate effectively } \\
\text { using a range of formats } \\
\text { relevant to scientists } \\
\text { demonstrate knowledge } \\
\text { of the major } \\
\text { physiological systems } \\
\text { and their adaptive } \\
\text { significance in animals } \\
\text { demonstrate } \\
\text { competence in a range } \\
\text { of laboratory and } \\
\text { practical skills }\end{array}$ \\
\hline $\begin{array}{l}\text { Total for } \\
\text { two focus } \\
\text { tasks }\end{array}$ & & $40 \%$ & $40 \%$ & $40 \%$ & \\
\hline
\end{tabular}


By week 5 of semester, students had completed the practical session which introduced and explained the expectations of the research manuscript. They had also completed four other practical classes (with practice practical test questions available), and so were nominally aware of what would be expected of them in each of the two flexibly weighted tasks. The size of the adjustment to percentage weighting of the two tasks was limited to $5 \%$, and the adjustment could not be applied to the unit's other assessment items. There was one other semester-based assessment item, worth $10 \%$ of the final grade and submitted in week 11 of semester, as well as a traditional end of semester theory examination $(50 \%)$.

Once a decision about weightings was made, it could not be adjusted. If a student wished to participate in the scheme, they were required to commit to an assessment regime by the end of week 5, that is, before they had completed either of the two focus assessment items (scientific manuscript research and writing task due in week 7 , and practical test completed in class in week 13). This commitment was voluntary, and recorded by completion and signature of a 'Flexible Assessment Agreement' (see Supplementary Material, Appendix 1), on which they indicated the assessment weighting pattern they wish to be applied to their assignments across the semester (Table 1). Regardless of participation or flexible option chosen, all students were required to complete all assessment tasks in the unit, and adhere to all normal deadlines, ensuring that they had the opportunity to address and demonstrate all ILOs by the end of the semester.

Data were collected from all enrolled students (including those who chose not to adjust their assessment pattern) using voluntary, anonymous (deidentified), paper surveys in the final practical session of semester 1 . The voluntary nature of the survey was conveyed to students verbally, by emails and in the unit outline. Surveys comprised a combination of yes/no, multiple choice and open-ended questions which allowed students to self-report about levels of motivation and engagement engendered by the opportunity to apply flexible assessment options to their semester-based assessment (see Supplementary Material, Appendix 2). Surveys were anonymous and were collected and retained by a staff member other than the researcher until unit results were finalised, to preserve respondent confidentiality

\section{Results}

Student response to the voluntary, paper survey was $96 \%$, with $79 / 82$ administered surveys returned. Of these, 5 were left blank, giving a participation rate for the survey of $74 / 79$, or $94 \%$. All results included below are percentages of this participation rate. Response rates varied slightly across individual questions: the mean response rate across individual questions and their parts was $89 \%$. For questions which generated open responses, the responses have been grouped thematically and are presented as a proportion of the total number of comments for each question. When an individual survey question included multiple comments, these were categorised individually, meaning that a single survey could give rise to more than one comment for each question. For example, if a student responded that they appreciated the opportunity to adjust assessment task weightings because it alleviated anxiety and it allowed prioritisation of workloads across units, this generated two separate comments under two distinct themes.

Of those who responded, $96 \%$ reported that they liked having the power to decide weightings on their assessment items (Survey Question 1, Appendix 2). The reasons for 
such strong support addressed several themes, with the most common reasons typified by the following comments:

"it is helpful to be able to work toward...strengths and reduce the pressure on something you may not be good at"

"if you know you are better at tests and if you are aware you will have more time to study in that stage of the semester it could give you the opportunity and incentive to do well"

Only three respondents suggested that they did not like the flexible assessment opportunity, typically remarking:

"... I worried that if I changed one what if I surprised myself and did better in the one I thought I would do worse in and it was worth less"

The majority of respondents (93\%) believed that this choice of assessment flexibility was something all students should have access to during their studies (Survey Question 2). The comments often demonstrated a broad awareness that fellow students might have differing skill sets, so that flexible assessment was acting to increase fairness, allowing all students to 'play to their strengths'. Comments suggesting an increased level of responsibility for, or ownership of, their own learning, were also frequently made:

"everyone is different and has different strengths and weaknesses. Flexibility compensates for this [resulting in] more fair assessment"

"promotes independent learning. Encourages students to be involved in learning process"

Some student responses (10\%) expressed a concern that making a flexible assessment choice might promote laziness in their fellow students, by encouraging less than maximal effort on all assessment tasks:

"students make lack in diligence of study in personally chosen areas".

Interestingly, despite a majority of students agreeing that the opportunities afforded by this kind of flexible assessment were positive, only $47 \%$ of those who completed the survey took up the opportunity to formally change their assessment weightings. Of those students who chose to make a change from the standard assessment pattern, many responded that they felt comfortable to make the commitment based on previous experiences of their skill levels for the two contrasting tasks, or that they were using the option to manage and prioritise their workload across the semester, anticipating how much time they would have to devote to various tasks as the semester progressed (Survey Question 3):

"I did really well in the prac test last semester, journal articles are scary"

"I can plan my time better for assignments. I knew I would be pushed for time around the prac test as it is towards then end of semester when many assignments tend to be due" 
For the $53 \%$ of the class who agreed that the idea of flexible assessment was definitely favourable, but who declined to take up the opportunity, there was a clearly expressed unwillingness to take what was perceived as a risk, that is, to make a commitment based on knowledge of self and skills, in either weighting direction, for fear of making the 'wrong' decision and reducing their final mark in the unit. There was also a notable proportion of students $(21 \%)$ who believed that they were neither stronger nor weaker in one of the focus tasks, based on their previous experiences, who elected to retain the default assessment pattern. Some students also reflected that they did not actually know their own strengths and weaknesses with respect to skills to each of the practical test and written manuscript tasks (Survey Questions 3):

"Was worried I'd do worse in the one I'd weighted more"

"I didn't think I had a particularly big strength in either area. I enjoy prac classes and usually do reasonably well in assignment writing"

"I'm not sure where my strengths are, (still figuring it out) so I stick with the standard assessment"

When students were asked, (before either of the assessment items were submitted) to nominate which of the two assessment tasks they believed was their 'strength' (Survey Question 4), there was no clear preference for either activity (and, therefore, skill set) and so, no perception among students that one task was less difficult than the other. Mean marks ultimately awarded for both tasks across the whole class supported this perception (manuscript task 66.6\%, practical test $61.5 \%$, both in the credit band). Quite a few students $(41 \%)$ believed they would perform more strongly on the scientific manuscript task, and $46 \%$ selected the practical test assessment item (Figure 1). While not actually offered on the survey as a choice, $7 \%$ of students indicated that they did not believe that they would perform either better or worse on a particular task, and an additional $7 \%$ left that question blank.

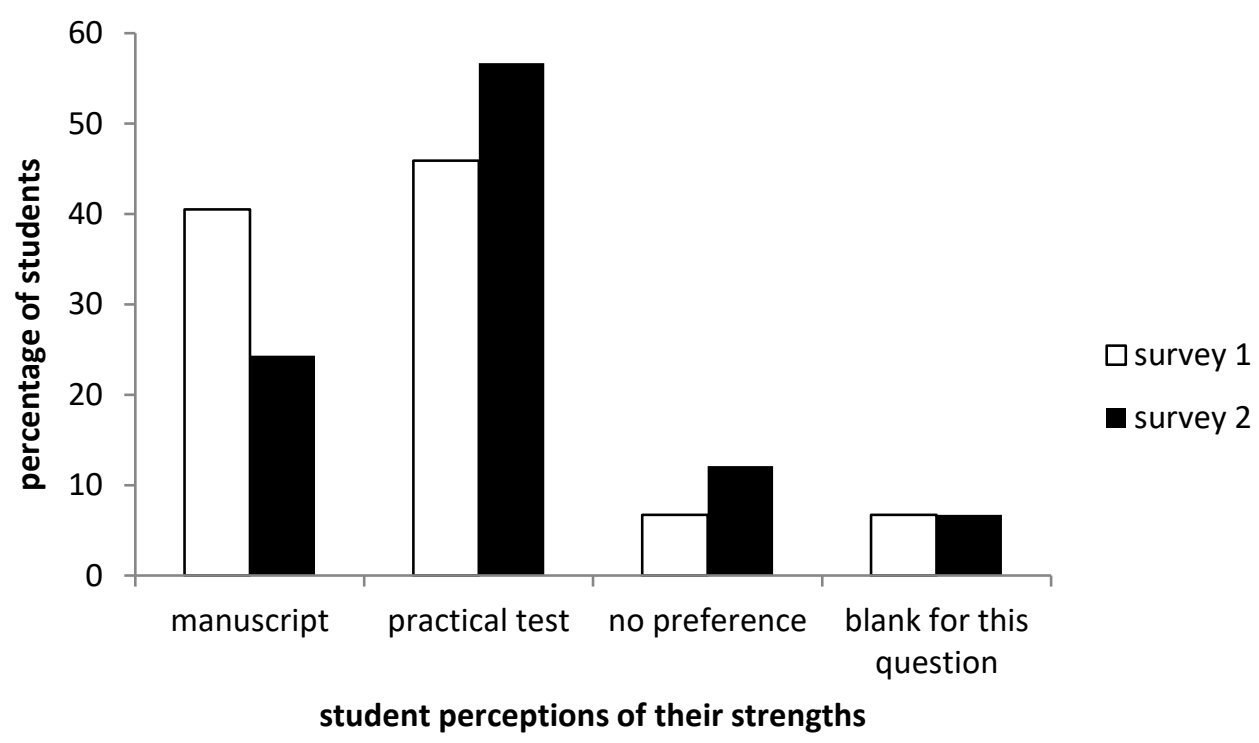

Figure 1. The percentage of students who nominated each task type as their perceived strength at the start and end of the data collection period. 
When the students were asked again at the end of the semester, having experienced and completed both assessment tasks, which they now believed was their 'strength' (Survey Question 5), there was a large shift in student perceptions. The most notable was a drop from $41 \%$ to $24 \%$ of respondents nominating the manuscript task as their perceived strength, and a rise from $46 \%$ to $57 \%$ now perceiving that their skill set favoured the practical test task (despite not having received the results of the practical test at the time when they completed the second survey) (see Figure 1). The data also indicated a small increase, from $7 \%$ to $12 \%$, in the proportion of students who indicated they did not have or were not aware of a perceived area of strength, after being given the opportunity to reflect on their experiences with each type of assessment task during the semester. Regardless of whether they achieved a higher mark in the task of their 'expected' strength, $27 \%$ of respondents reported changing their perceived strength between the choices offered in this case (Figure 1). Interestingly, not all students had an accurate perception of their relevant strengths at the start of the semester, with only $60 \%$ of students making the choice which achieved the higher result on the more heavily weighted task.

When students were asked whether they would choose to adjust assessment weightings in future, if given an opportunity (Survey Question 6), 84\% responded that even if they had elected not to use flexible assessment on this occasion, they would in the future. The most common reasons for this are typified by the anonymous feedback comments below:

"now with a clearer understanding of my strengths I might risk adjustments"

"it is nice knowing you have a choice and it gives some piece of mind. For example, had I chosen to weight the MS more heavily, I would have less pressure towards the end of semester for the prac test, as it coincides with other unit tests"

Of the remaining respondents, those who indicated that they would NOT take up a flexible assessment option in the future, very few offered explanatory comments, but the most common reasons given indicated a perception that assessment was less fair if students could change it, that it might encourage either themselves or other students to put in less effort on some tasks, or that they still were not willing to take the risk of doing themselves a disadvantage with their final result:

"I feel with a lesser \% weighting I would put less effort into that assignment than the higher. Would rather put as much effort into both"

"honestly I couldn't choose because I said if I do really well in the prac test and not on the assignment but I made the assignment worth more I would SO kick myself!"

The final survey question asked about student perceptions of the impact of the flexible assessment opportunity on their motivation for and engagement with the unit (Survey Question 7). Half the respondents (51\%) indicated that they felt themselves to be more engaged and motivated as a result of the offer of flexible assessment. Some respondents explained that increased feelings of autonomy over their own learning, and the associated reduced anxiety about assessment were responsible for this perception:

"being offered greater responsibility and flexibility in this unit in fact did motivate me to engage in many aspects of this course and in study in general" 
"I felt like I had a say in how I learnt and was judged"

"...I was less stressed in pracs which made them more positive"

Of those who responded negatively to this question, comments that those students were already motivated and engaged were common:

"I was engaged because the unit is enjoyable, not because of changing the weightings of an assessment"

"not more engaged or motivated but definitely like I had more control over my degree if I wished to exercise it"

"both assessments are still important. I still aimed to get my best marks possibly for each assessment"

Internal assessment distributions in this unit were unchanged by allowing students to have input into their assessment pattern. Figure 2 indicates the final internal (excludes examination worth $50 \%$ of final result) distributions of marks both before and after flexible assessment was applied to the results of those students who selected it (47\%). There were no changes to the number of students who did not achieve $50 \%$ or higher in their semester-based assessment, nor to the number scoring in the highest mark band: normal distribution was retained under both scenarios.

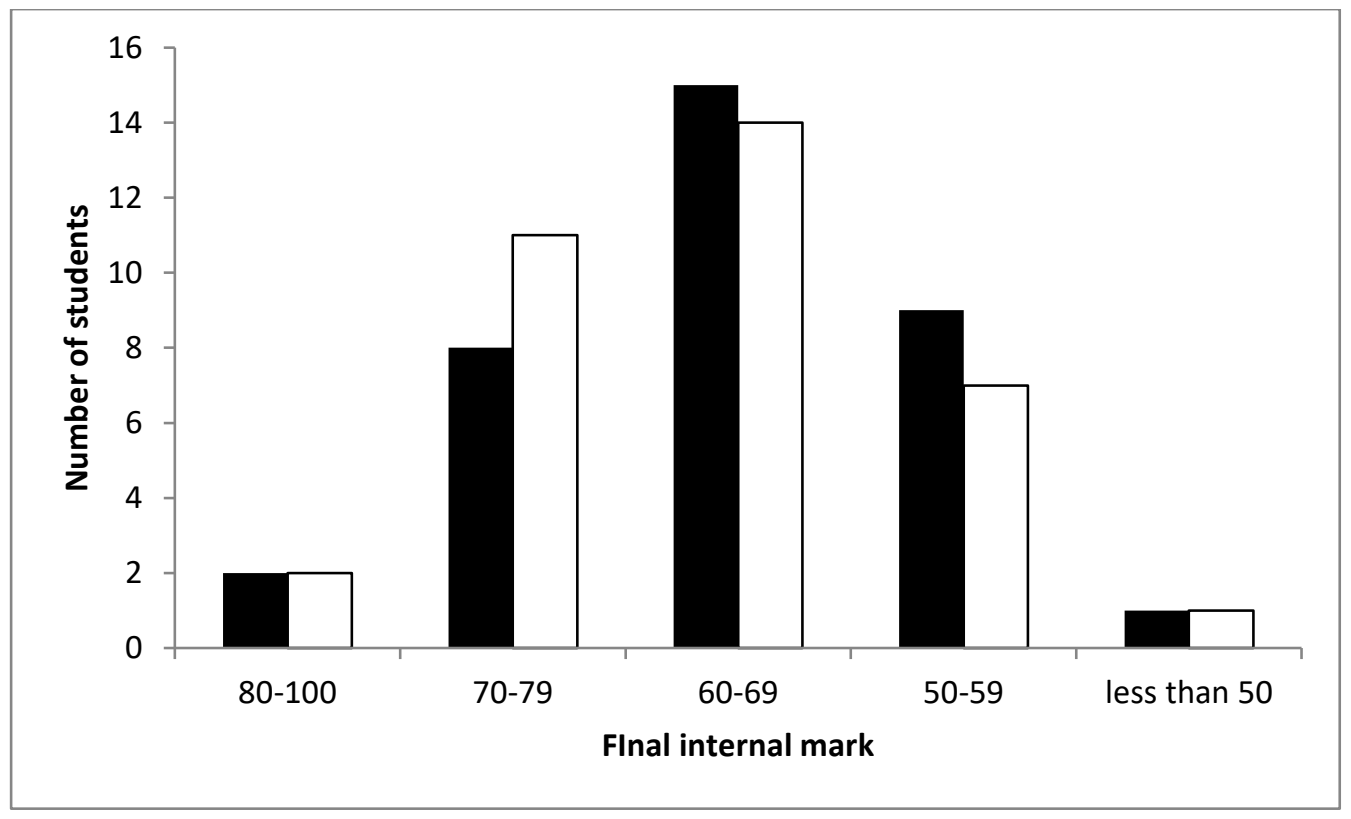

Figure 2. Distribution of final internal assessment results (excludes examination) for students who chose to make a change to their assessment weightings (35 students, $47 \%$ of participants), comparing the application of flexible assessment (black) with how the results distribution would have looked under the standard assessment pattern (white). 


\section{Discussion}

This study showed that flexible assessment opportunities for students can result in selfreporting of increased motivation and engagement over a semester-based subject delivery. Flexible assessment in the format described here, in which students had the opportunity to play to their strengths by adjusting weighting of assessment items, addresses several factors affecting motivation and so, student engagement. For example, motivation and engagement can be negatively impacted by stress and anxiety (Gibbs, 1992), both of which are typically increased by the perceived pressure of assessment tasks (Rust, 2002). The opportunity to lower the weighting of a nominated task (which the student reflected was NOT a personal strength) by just 5\%, demonstrably reduced the pressure felt by students, reducing anxiety and increasing enjoyment and engagement. Flexible assessment offered in the format described here addresses many of the needs and concerns of previous authors, by being valid and transparent (MacLellan, 2004) for those who chose to participate, by maintaining the benefits associated with timely feedback (Gibbs \& Simpson, 2004), and by allowing students of diverse backgrounds to tailor a personalised and accessible assessment pattern (Irwin \& Hepplestone, 2011).

Engagement with learning opportunities can also be enhanced by offering intrinsic motivators such as autonomy and choice (Zepke \& Leach, 2010). Many students in this flexible assessment study indicated that being offered, and/or choosing to take, the power to make decisions concerning their assessment was not only a powerful motivator, but also a kind of informal resolution to work harder than they might have otherwise, a demonstration supporting Ryan and Deci's (2000) discussion of intrinsic motivation leading to the inherent enjoyment derived from challenging one's self.

Assessment can have a greater impact than any other factor on how effectively students learn (Boud, 1981). More particularly, student perceptions of assessment have the potential to negatively influence motivation to learn, and engagement with learning opportunities (Ramsden, 1992). Motivation and engagement over a sustained period such as a university semester present challenges to both teachers and students (Meece, Blumenfield \& Hoyle, 1988). Motivation, whether it is intrinsic (a natural inclination to seek new experiences and challenges for enjoyment (Ryan \& Deci, 2000)) or extrinsic (in a higher education context: to pass a test) (Deci, Nezlek \& Sheinman, 1981), can impact students' willingness and ability to engage with peers and learning opportunities in an educationally meaningful way (Hart et al., 2011). University teachers can be most effective by addressing variables influencing intrinsic motivation (the carrot) when looking to improve student engagement (Utman, 1997), while extrinsic motivating factors (the stick) have previously been associated with lowered learning outcomes (Cook, 2001; Ackerman et al., 1997).

Many students in this study made strategic decisions about the stage of the semester in which they wanted to attempt more heavily weighted tasks. They utilised flexible assessment options to juggle or manage their workload across subjects and other demands on their time. This, and other, aspects of autonomy and choice functioned to ameliorate the negative impacts of stress and anxiety associated with assessment, while simultaneously enhancing feelings of control, power and choice. These positive attributes have been demonstrated to increase student engagement (Brown, Bull \& Pendlebury, 1997; Gibbs, 1992) and result in improved learning outcomes as students participate more 
and gain better understanding of material when steps are taken to actively engage them (Ahlfeld, Mehta, \& Sellnow, 2005).

Reflections on offering flexible assessment opportunities to undergraduate students. Low uptake - Student data revealed some complex but somewhat intangible interactions which raise the following issues, and which will require further study. One finding was that while most students liked the idea of flexible assessment, less than half took up the opportunity to reweight their semester-based assessment profile. Part of this is attributable (from student comments) to fear of the unknown: many students in the current study reflected that once they had seen the innovation 'in action' across a semester, they would definitely participate if offered the opportunity in future. Choice itself, for some, can be stressful (Francis, 2008), an inherent risk of offering any flexible assessment opportunity. To mitigate this, Francis (2008) suggests that students' receptivity to the offer of empowerment is strongly related to progression through their degree program, with greater, and different types of readiness for choice demonstrated when comparing first and third year students. A scaffolded delivery of flexible assessment opportunities, with low stakes changes available in first year, building to more significant levels of choice and assessment autonomy as students progress, could well see increases in participation rates (and associated benefits) over time.

Independence and responsibility for own learning - Another part of the low participation rate may be explained (based on student comments) by students being unwilling to take the risk and so the responsibility for making changes to assessment task weightings. Numerous students expressed the concern of potentially doing themselves a disservice in the calculation of their final result by not knowing well enough where their stronger skill set lay, so not being in a position to 'play to their strengths'. The validity of this position was borne out by the results $(60 \%$ of students chose to increase the weighting of the task in which they scored the lower mark). Given that students, when offered choice, do not always make the best choices (Cook, 2001), at what stage in their maturation and development as learners might they be ready to take on this responsibility? Autonomy can come in several guises, from choice of assessment method, to self-determination of assessment criteria or topic (Francis, 2008). Learners at different stages of their degree, as they gain in self-confidence and an improved understanding of their own learning style and strengths, are likely to view autonomy as an advantage, rather than a risk. Offering a 'You can't lose' clause here might reduce fear of making the commitment and the reluctance to trust their understanding of their own knowledge and skills. A scenario in which, should the student inadvertently score lower than their own prediction in a reweighted assessment task, and so potentially be disadvantaged in the calculation of their final grade, that their assessment would revert to default weightings, could increase participation rates in the innovation and allow more students to benefit from being invited to reflect on their strengths and weaknesses as learners.

Getting over the fear of relinquishing control as the 'teacher' - It is entirely possible that this teacher's own fear of relinquishing control, which resulted in the designation of $5 \%$ as an appropriate reweighting flexibility to offer, may have contributed to the low participation rate. For some students, such a low-weighted change may not have been sufficiently tempting to elicit participation and may have prevented some from experiencing the benefits reported by participants. What weighting change is an appropriate one to offer students? That is, how big a change in assessment weightings are teachers willing to offer, and how big would this change need to be to be truly worthwhile 
and attractive to students? Offering larger potential weighting adjustments, whilst maintaining coverage of ILOs, might afford increased success in embedding flexible assessment into the semester-based assessment for Biology students, but the barrier of relinquishing control over the equality of the student experience can be difficult for teachers to pass (Lee, 2011).

\section{Summary and conclusion}

In 2012, Irwin and Hepplestone called for additional research into flexible assessment formats as a potential source of strategies to address these concerns. As time spent on university campuses decreases (Hart et al., 2011), and student attention spans also decrease (Ahlfeld et al., 2005), it is becoming increasingly challenging, and increasingly important, to design and deliver learning opportunities which actively engage students. Research into the effects of personalising the learning process suggests that emphasis on an understanding of self and the way one learns have positive and measurable outcomes with respect to performance in assessment pieces (Roberts, 1975). The way learning is assessed can have a strong and significant effect on student perceptions or themselves and their learning, and also on their levels of motivation and engagement (Cook, 2001). Flexible assessment (as undertaken in this study) can provide an additional item in the toolbox of strategies with which teachers can address the challenges of motivating and engaging students.

\section{Acknowledgements}

This study was conducted under University of Tasmania Human Research Ethics Committee approval number H0014642. Thank you to Prof. Sue Jones and Assoc. Prof. Andrea Carr, Prof. Brett Gartrell and Assoc. Prof Fiona Bird for feedback on earlier drafts of the manuscript. Particular thanks go to the students for their feedback and comments.

\section{References}

Ackerman, S., Hughs, L. \& Wilder, R. (1997) Improving student responsibility. Unpublished Masters action research project, St Xavier University, Chicago, Illinois, May 1997

Ahlfeld, S., Mehta, S. \& Sellnow, T. (2005) Measurement and analysis of student engagement in university classes where varying levels of PBL methods of instruction are in use. Higher Education Research and Development 24(1), 5-20. doi.org/10.1080/0729436052000318541

Boud, D. (1981) Moving toward Autonomy: Developing student autonomy in Learning, in D. Boud (Ed), Kogan Page, London/Nichols Publishing Company, New York, pp 17-39.

Brown, G., Bull, J. \& Pendlebury, M. (1997) Assessing student learning in higher education. Routledge, London and New York.

Caitlin, K., Lewan, G.J. \& Perignon, B. (1999) Increasing student engagement through goal-setting, cooperative learning and student choice. Masters Thesis, Saint Xavier University and Skylight Professional Development Field-Based Masters Program, Chicago, Illinois, May 1999. Abstract only. https://eric.ed.gov/?id=ED433100

Cook, A. (2001) Assessing the use of flexible assessment. Assessment and Evaluation in Higher Education 26(6), 539-549. doi.org/10.1080/02602930120093878

Deci E.L., Nezlek J. \& Sheinman L. (1981) Characteristics of the rewarder and intrinsic motivation of the rewardee. Journal of Personality and Social Psychology 40(1), 1-10. doi.org/10.1037/00223514.40.1.1

Francis R.A. (2008) An investigation into the receptivity of undergraduate students to assessment empowerment. Assessment and Evaluation in Higher Education 33(5), 547-557. doi.org/10.1080/02602930701698991 
Flink, C., Boggiano, A.K. \& Barrett, M. (1990) Controlling teaching strategies: Undermining children's self-determination and performance. Journal of Personality and Social Psychology 59(9), 916-924. DOI: $10.1037 / 0022-3514.59 .5 .916$

Gibbs, G. (1992) Improving the quality of student learning. Technical and educational services Ltd, Bristol, UK.

Gibbs, G. \& Simpson, C. (2004) Conditions Under Which Assessment Supports Students' Learning. Learning and Teaching in Higher Education 1, 3-31. DOI: 10.1007/978-3-8348-9837-1

Hart, C., Hammer, S., Collins, P. \& Chardon, T. (2011) The read deal: Using authentic assessment to promote student engagement in the first and second years of a regional law program. Legal Education Review 21(1), 97-121.

Irwin, B. \& Hepplestone, S. (2012) Examining increased flexibility in assessment formats. Assessment and Evaluation in Higher Education 37(7), 773-785. doi.org/10.1080/02602938.2011.573842

Lee, V.S. (2011) The power of inquiry as a way of learning. Innovative Higher Education 36, 149-160. doi.org/10.1007/s10755-010-9166-4 https://epublications.bond.edu.au/ler/vol21/iss1/6

MacLellan E. (2001) How convincing is alternative assessment for use in higher education? Assessment and Evaluation in Higher Education 29(3), 311-321. DOI: 10.1080/0260293042000188267

Martin A. (2009) Motivation and engagement across the academic lifespan. Educational and Psychological Measurement 69(5), 794-824. doi.org/10.1177/0013164409332214

Meece, J.L., Blumenfield P.C. \& Hoyle, R.H. (1988) Students' goal orientations and cognitive engagement in classroom activities. Journal of Educational Psychology 80(4), 514-523. doi.org/10.1037/0022-0663.80.4.514

Ramsden D. (1992) Learning To Teach in Higher Education. Routledge, London and New York.

Roberts, D.Y. (1975) Personalizing learning processes. Paper presented at the annual meeting of the American Association of Community and Junior Colleges (Seattle, Washington, April 13-16, 1975, 9 pages). https://files.eric.ed.gov/fulltext/ED115322.pdf

Rust, C. (2002) The impact of assessment on student learning. Active Learning in Higher Education 3(2), 145-158. doi.org/10.1016/j.sbspro.2011.11.133

Ryan, R.M. \& Deci, E.L. (2000) Self-determination theory and the facilitation of intrinsic motivation, social development, and well-being. American Psychologist 55(1), 68-78. doi.org/10.1037/0003066X.55.1.68

Utman, C.H. (1997) Performance effects of motivational state: A meta-analysis. Personality and Social Psychology Review 1(2), 170-182. DOI:10.1207/s15327957pspr0102_4

Wood, L.N. \& Smith, G.H. (1999) Flexible assessment. Paper presented at The Challenge of Diversity: The Delta 99 symposium on undergraduate mathematics, November 23, in Queensland, Australia. (Eds. Spunde, W., Cretchley, P. \& Hubbard, R.). Laguna Quays: University of Southern Queensland Press, 229-233. http://www.sci.usq.edu.au/staff/spunde/delta99/Papers/wood_s.pdf

Zepke, N. \& Leach, L. (2010) Improving student engagement: ten proposals for action. Active Learning in Higher Education 11(3), 167-177. doi.org/10.1177/1469787410379680 